\title{
Roadmap to Stop the Predatory Journals: Author's Perspective
}

\author{
Amin Talebi Bezmin Abadi \\ Department of Bacteriology, Faculty of Medical Sciences, Tarbiat Modares University, Tehran, Iran.
}

Received: 29 Dec 2016

Revised : 14 Jan 2017

Accepted: 26 Jan 2017

Corresponding Author: Amin Talebi Bezmin Abadi Tarbiat Modares University, Dept of Bacteriology, P.O. Box: 14115-111, Tehran, Iran

Phone: +98-21 82884883

E-mail: Amin.talebi@modares.ac.ir

\begin{abstract}
Recent disgracing reports are warning the scientific communities to think more about the solutions to win the battle against predatory journals and publishers. Current integrity and accuracy in science is a result of decades of honest works and publications which are an asset, now everyone as stakeholders of science should feel the responsibility to sustain its high privileged level. The ethical sides of this duty need careful considerations by science stakeholders worldwide. Boosting the weak resume, getting higher and faster promotion and permanent jobs in academia cannot figure out as reasonable excuses to publish unethically. Hereby, I suggest a practical roadmap based on certain strategies which are recommendable for the scientific community. This paper describes author's perspective about predatory journals and how we can stop them. Moreover, following appearance of predatory journal, this is first article discussing root cause analysis on this global scientific problem. Last but not least, predatory journals are not too bad! Since they can be considered as critical discriminatory tool to distinguish between individuals who work truly standard and who pretend to work standard.
\end{abstract}

Keywords: Predatory Publishing; scientific misconduct; peer-review; Open Access; Scientific reputation; Education; Policy

Please cite this article as: Talebi A. Roadmap to stop the predatory journals: Author's Perspective. Res Mol Med. 2017; 5 (1): $1-5$

\section{Introduction}

Introduction of the disaster

To be a scientist, one usually needs the journals which are relatively differed in their scientific contents, reputations, indexing databases, scopes, leaderships and interested readers. Apart from both i) how good scientists design their studies, ii) how to run the researches, importance of finding the suitable journals for publishing the manuscripts has been never considered well enough. Indeed, we cannot speak about academic publishing with no mention of the journals. This subject may be listed as forgotten issue in academic atmosphere. Undermining this issue during the last decade resulted in many scientific disgraces in universities and institutes all over the world (Bowman 2014; Cariappa and Kumar 2015; Eriksson and Helgesson 2016). Unfortunately, same as other areas, scientific writing can be also a target of corruptive actions (Jones and McCullough 2014). One of the main concern in academic publishing is existence of problematic journals which called "predatory journals". They are exploiting the open-access (OA) model by corrupting the peerreview process, which is not actually undertaken (Beall 2012). Honestly, publish or perish phrase, desire of publishing more and open access movement were three determining reasons for appearance of predatory journals. These are major threats for integrity of academic literature. Recent reports from various countries showed that a global call is necessary to address the problem and then finding a solution to deal with these harmful phenomena in science. The exact objectives of this article are; i) to see how authors can recognize this false academy and then stemming the disaster caused by predatory journals, ii) further, I want to have a root cause analysis (RCA) investigating why predatory journals appeared and welcomed by some authors. At final, it should be possible to have a realistic roadmap to defeat predatory journals. In order to see how the predatory journals flourish, we need first to see how 
the open access option facilitates the emergence of a long list of predatory journals.

Open access: threats or opportunities?

The term 'Open Access' (OA) was first applied for journals in 2002 by the Budapest Open Access Initiative which sought to accelerate progress internationally to make papers freely available on the web (Swan 2012). OA is a type of publishing launched by scholarly and peer-reviewed journals that relies on sources of funding other than subscription fees (Nicoll and Chinn 2015). There have been three models for open-access publishing reported so far (Crow 2009). The first one is the gold model (gold open access). In the gold model, the submission is financially supported by institute/author, thus the cost (ranged from 100 up to the 2000 dollars) will be paid upon the acceptance of the paper (Frantsvåg 2010). The green model (green open-access) is an author self-archive system which usually provides author's final draft in Word, not in PDF version) in open-access institutional and disciplinary repositories. The last model of scholarly open-access publishing is relatively same as gold model, but without payment (Some people call it platinum open access). One of the lacking feature of golden open-access model is that one is suspicious on the common believe that is more accepted papers is close to more money! In practical settings, new emerging publishers are exploiting gold open-access model to only earn money. They are corrupting the science only for their own profits. While we admit that the movement from traditional subscription model to open access has large amount of benefits, control and management of this long list of questionable journals is not an easy task for science stakeholders worldwide. Possibly one of the key difficulties is the dissemination of 'predatory journals" that publish scientific reports with zero or minimal quality control (Stratford 2012). Exploiting the scientific publication is a recent phenomenon that emerged following the OA model of the academic publishing. Since in OA model, author is the one who pay directly, it became the start point of fraud and scamming in academia. To be honest, this model was the mostly profitable strategy adopted by predatory journals. For first time, American associate professor, Jeffrey Beall provided the long List (http://scholarlyoa.com/), to monitor and check standalone journals and publishers (Beall 2015). Later, he listed thousands questionable open access journals. Whether everyone pleased or not, beall $\mathrm{s}$ list arise many attentions and concerns to the case of predatory journals and misuse of OA. The main goal targeted by beall is to fight against those bogus journals and guide the people to recognize them among the many reputable available journals to publish. Conclusively, OA model of publishing is basically useful option for authors, but it needs large amount of attentions for not being misused by predatory journals. But, how we can protect authors from extensive arrays of this damage?

\section{Roadmap with four steps to rein the disaster}

To protect scientific space, especially authors from deleterious effects of predatory journals, I aim to define a roadmap standing with four steps to stop predatory journals in the near future.

\section{1-Ignorance of "publish or perish" motto}

We know that scientists like to boost their reputations, thus they bind to be productive in high ranked journals. Surely, scientists are not same and some are easily able to publish in high impact factor journals, but some are not! In a competitive space, not on purposely, this loser researcher in publishing is under pressure (which is unethical) to consider shortcuts for increasing the number of papers. Normal advice to publish is established and recommendable, but it the case of too much pressure, the result may be a scientific fraud. As such, the scientists are struggling with intolerable moral feeling to boost his/her CV with those papers publishable in predatory journals for some dollars! All this problem is a fruit of "publish or perish" motto! It is like a metastatic tumor in science! We should make a cultural promotion in our scientific atmosphere in parallel with scientific progress. These are two wings for flying! We need both to develop our community in parallel with ethical knowledge. Accordingly, in first step, institutes and science decision-makers around the world should ignore the traditional policy for counting only the number of published papers as the main way to evaluate faculty members. They are strongly recommended to see how many high impact factors papers with too many citations existed in author s resume. Publish or perish should be ultimately forgotten motto since it is defeated policy which its advantages are lesser than its disadvantages.

\section{2- Decrease quick decision on submission}

One of the moral problems which facilitate misuse by predatory journals is that author's quick decision to publish the results at any cost! Spending one year of performing the experiments absolutely deserve a one week of search in databases to find legitimate and high impact journal to submit! It should be counted as a benefit of the research to submit at the end! So, by spending time to find a valuable journal, we make the choice which ending in acceptable scientific achievement. However, in last years of being a $\mathrm{PhD}$, students are under different kind of pressures to finish 
the course as soon as possible. This pressure should not be ended in quick decision on submission of the available findings which are mostly inappropriate to be published. This issue should be considered by authorities in universities as well.

\section{3- Prevention is always cheaper than therapy!}

Following this subtitle, we should encourage researchers and scientists to recognize the predatory journals rather than complaining them after publishing. In below, I provided the most apparent signs of being a predatory journal. No one can guarantee that journal having any of these signs is predatory, but provided points can help a wise person to easily suspect the journal and scrutinize it before submitting.

1. Absolute amateur website design

2. Long list of publishing scope ranged from law to microbiology

3 . Not clearly stated about publication fee

4. Mostly invite junior researchers or $\mathrm{PhD}$ candidates to submit

5. Science, World, American and Global are the frequently used words in journals names

6. Lack of established policies against predatory publishers

7. Unfamiliar editor or editor in chief names!

8. Negotiable charge fee!

9. Sending unsolicited invitations with general title and many grammatical errors

10. Indexed in unfamiliar databases or even not really existed ones

11. Mostly long and meaningless names for the journal

12. Non-academic advertisement in the homepage of the journal

13. Mostly without archive or past issues

14. Lack of reputable editorial board

15. Immediate response after first reply

16. Inviting to write editorials or letter to the editor!

17. Using the word "professor" to fool the authors in all corresponding emails

18. Quick peer review (1-2 days) if exists at minimum!

19. Exaggerated impact factor calculated by formulations from misleading metrics companies

20. Many grammatical errors in published papers

21. Frequently using Gmail or Yahoo to contact authors

22. Writing about acceptance date even before submission

23. Having a close deadline for submission

24. Not being in the Directory of Open Access Journals (DOAJ)

25. Talking about your recent publication and invite you to write a paper
26. Using email to send the paper rather than other acceptable online submission systems

\section{4- Being an expert in your field}

No doubt that it is useful to be expert and focused in specific field and continue it for years. It is easy to imagine that researchers can become an expert because of reading and briefing many papers/review articles in interested field. Suppose that authors daily visiting groundbreaking papers in journals from the field that only cite reputable literature from validated indexing databases. As note, expert scientists are regularly receiving alerts of citations from those respectful journals. Of course, these people are really in to the journals and familiar with them. They know what they want, so it is easier to stand in comparison with situation that investigators are making arbitrary research and trying to write a paper which can be only accepted in a predatory journal. This strategy can assist investigators to, 1- be familiar with famous journals and their names at least! So they never going to be fooled by fake invitation of predatory journals, 2- one knows how to do research and get promoted in right way, and 3- author will immediately noticed about predatory journals if he/she checks the editorial board of the journal. Most of professional scientists know well-enough about journals they aimed to submit their manuscripts. In other words, authors who think deeply about their interests and then following their research fields are indirectly protecting themselves from the threats of predatory journals. Thus, good researchers who design a good study should be able to find good journal to publish it. Shaping the thoughts to write a good proposal is a guarantee to have an honorable publication at the end. This strategy (being expert in research field) should be quickly disseminated among the young researchers and junior faculty members to encourage for making true science.

\section{Root cause analysis (RCA)}

To see why predatory journals appeared in last years, we should have a look in to the root cause of the problem. Indeed, we have most reports of predatory journals from developing countries (Talebi Bezmin Abadi, A et al, unpublished data). One of the issues is the low quality of research undertaken in developing countries. Thus, weak financial support and lack of basic structures for novel studies are the other reasons which those countries are the main sources of fans for predatory journals. Of course, only good research should be published in good journal. It is highly expected that weak and not well-designed researches have to target those questionable journals. We know that in many developing countries science ministries and affiliated authorities are inviting their scientists 
to publish only in reputable journals, but as we already mentioned, lack of fundamental facilities, financial supports and also weak novelty of studies are three main causes of not having good papers reputed journals. Later, only predatory journals can be available options for people who have not enough integrity with ethical standards in publishing their manuscripts. In brief, we have to still write papers about predatory journals if we unable to provide those supportive and useful resources for all researchers in low and medium income countries. Looking thoroughly to find the suitable journals among predatory ones is not an easy task. Accordingly, we need to first request to call for being awake about this threat. Later, smaller groups from each expertise can help inexperienced scientists to detect predatory journals in every department worldwide. Science needs its individuals to work and it is a critical task for authorities to only hire people with enough eligibility for science.

\section{Conclusive comments}

We need to inspire a spirit of right type of publishing among the candidates before they start academic activities or became a major victim of predatory publishers. These suggestions need to be considered by country decision makers all over the world. Noted, paying attention to these suggestions only by a country in Asia or Europe cannot solve the problem at all. To be realistic for solving the problem, we should have addressed the scientists for their lacking in increase their knowledge on predatory journals rather than only blaming the journals! In this regard, those scientists should be noticed that they are selling whole their years of well-reputations instead of couple of publications which is absolute lose - lose situation. In developing countries same as developed countries, we need to launch policies about junior faculties to prevent contaminating by this shady stigma. In other words, training this high risk group should be in priority, meantime we need to take care of $\mathrm{PhD}$ students and independent investigators in research institutes as well. In order to have different angle in this global problem, we can understand why all researchers are standing to make more publication with higher quality. Recently, many scientometrics tools (Scopus, Researchgate, ORCID, Google Scholar, and Web of Science) to measure and analysis the innovations and publications produced by researchers had been invented. Thus, everyone can easily access to see how well or bad are others and how far stand from each other in $\mathrm{H}$. index, number of citations or recent published papers. This new and competitive space is constructive basically, but can be a bit deceptive for who are not really in to the science. This is a concern that science stakeholders should pay attention to it and trying to remove sideeffects of these competitions. 'Publish less but effective" (more citations in reputable indexing databases) should be adopted as new motto instead of publish or perish as traditional useless policy which is a one of main cause of increased publication misconduct in last years. Science is necessarily an ethics-based concept which requires considering different features of standard publishing. What we heard already is without ethics that is equal to the "'Pseudoscience', All fraudulent points we addressed in this article are about corruption, deception and fraud which never should be colonized in science. As who claim to establish ethically right science, we all are responsible to first teach others and also disseminate proper culture of true science. Current integrity and accuracy in science is a result of decades of honest works and publications which are an asset, now we, as stakeholders of science should feel the responsibility to sustain current highly privileged level. Last but not least, predatory journals are not too bad! Since they can be considered as critical discriminatory tool to distinguish between individuals who work truly standard and who pretend to work standard.

\section{Acknowledgment}

The content of this article is sole responsibility of the author and necessarily represent personal prospective.

\section{Conflict of interest}

The author has declared that no competing interests exist.

\section{References}

1. Beall, Jeffrey. 2012. Predatory publishers are corrupting open access. Nature 489 (7415):179. PMID: 22972258

2. Beall, Jeffrey. Criteria for determining predatory open-access publishers. Scholarly open access. 2015.

3. Bowman, John D. Predatory publishing, questionable peer review, and fraudulent conferences. Am J Pharm Educ. 2014; 78 (10):176. PMID: 25657363

4. Cariappa, MP, and Narinder Kumar. Predatory publishing: Writers beware! Med J Armed Forces India. 2015; 71 (3):300-1. PMID: 26288502

5. Crow R. Income models for open access: An overview of current practice. Washington: SPARC. 2009.

6. Eriksson, Stefan, and Gert Helgesson. The false academy: predatory publishing in science and bioethics. Med Health Care Philos. 2016; 20(2): 163-170. PMID: 27718131

7. Frantsvåg, Jan Erik. The role of advertising in financing open access journals. First Monday. 2010; 15 (3).

8. Jones, James W, and Laurence B McCullough. Publishing corruption discussion: predatory journalism. J Vasc Surg. 2014; 59 (2):536-7. PMID: 24461869 
9. Nicoll, Leslie H, and Peggy L Chinn. Caught in the trap: The allure of deceptive publishers. Nurse Author \& Editor. 2015; (4):4.

10. Stratford, Michael. Predatory" online journals lure scholars who are eager to publish. Chron High Educ. 2012.

11. Swan, Alma. Policy guidelines for the development and promotion of open access. UNESCO. 2012 